\title{
Colonic myoelectrical activity in man: comparison of recording techniques and methods of analysis
}

\author{
C. J. STODDARD ${ }^{1}$, H. L. DUTHIE, R. H. SMALlWOOD, AND D. A. LINKENS \\ From the Departments of Surgery, Medical Physics and Control Engineering, University of Sheffield, \\ Sheffield
}

SUMMARY Both monopolar and bipolar recordings of human colonic myoelectrical activity have been made on 29 occasions from implanted serosal electrodes attached to either the ascending colon or transverse colon. Visual and computer analysis of the signals were made and the incidences of the two electrical rhythms present in the colon were compared for the two recording techniques, recording sites, and methods of analysis. The percentage incidence of both rhythms was similar for the mono and bipolar recording techniques in both parts of the colon. The incidence of the two rhythms in the transverse colon was approximately twice that recorded in the ascending colon, this being true for both recording techniques and methods of analysis, but neither was detected for more than $50 \%$ of the time. It is concluded that the methods of data analysis probably account for the differing incidences of electrical activity in the human colon that have been reported previously.

Rhythmic fluctuations in electrical potential, known as slow waves, are present in the smooth muscle of all parts of the gastrointestinal tract except the oesophagus. Their function is to co-ordinate adjacent cells so that an effective contraction will be initiated when depolarisation occurs. The slow waves in the stomach and small intestine in man (Kwong et al. 1970; Waterfall et al., 1973) and dog (Daniel et al., 1959; Kelly et al., 1969) have a clear pattern, being both regular and continuous. Colonic electrical activity is more variable and there is disagreement about the slow wave frequency, percentage occurrence and number of rhythms that can be recorded from the human colon in vivo. Taylor et al. $(1974,1975)$ and Snape et al. (1976) reported that regular slow wave activity is not present at all times and that two rhythms are present, a predominantly higher one at 0.1 to $0.2 \mathrm{~Hz}$ (6 to 12 cycles/min) and one at a lower frequency of 0.033 to $0.066 \mathrm{~Hz}$ ( 2 to 4 cycles/min). This has been disputed by Bardakjian et al. (1976) who stated that slow waves in the ascending colon are omnipresent and have only one rhythm at a frequency of approximately $0.06 \mathrm{~Hz}(3.5 \mathrm{cycles} / \mathrm{min})$. Bowes et al. (1978) believe that in the canine colon slow waves occur only at 0.05 to $0.066 \mathrm{~Hz}$ (3 to 4

${ }^{1}$ Address for reprints: C. J. Stoddard, University Surgical Unit, Hallamshire Hospital, Sheffield S10 2JF, England.

Received for publication 30 November 1978 cycles/min) and that the higher frequencies observed are the harmonics of this slower rhythm.

It is possible that differences in the recording techniques and methods of data analysis may explain those apparent discrepancies. Analysis may be performed visually, which is the least complex but laborious and open to subjective variation, or by computerised techniques (Linkens, 1978). Monopolar recordings were made by Taylor et al. (1975) and these were analysed both visually and by frequency analysis using a fast Fourier transform technique (FFT), whereas the bipolar recordings of Bardakjian et al. (1976) were analysed only by FFT without any visual analysis of the 'raw' electrical signals. In this present series, we have made both monopolar and bipolar serosal recordings from the ascending and transverse colons of consenting patients and compared the visual and FFT methods of data analysis.

\section{Methods}

RECORDING TECHNIQUES

A total of 20 patients, 14 females and six males, aged 29 to 64 years and who were undergoing elective surgery for cholelithiasis, were studied. Informed consent was obtained from all patients after approval by the Ethical Committee. After the cholecystectomy was completed, two pairs of stainless steel electrodes were implanted under the 
serosal surface of the bowel, each being held in position by one 000 plain catgut suture. In 14 patients, each pair was implanted in the taenia coli of either the ascending or right half of the transverse colon perpendicular to the long axis of the bowel. In the ascending colon the electrodes were implanted at its mid-point (proximal) and $5 \mathrm{~cm}$ below the hepatic flexure (distal). In the transverse colon the electrodes were implanted $5 \mathrm{~cm}$ beyond the hepatic flexure (proximal) and at its mid-point (distal). In the remaining six patients, one pair of electrodes was attached to the ascending colon and one pair to the first part of the duodenum. The interelectrode distance between each electrode in a pair was $1 \mathrm{~cm}$. The connecting wires were exteriorised along with a right hypochondrial rubber drain. Electrodes, wires, and drain were uneventfully removed from all patients on the fifth postoperative day after recordings had been made.

One or two recordings of two hours duration were made from each patient on the second to fifth postoperative days. Monopolar and bipolar signals from each pair of electrodes were fed into amplifiers with a frequency response within $\pm 3 \mathrm{~dB}$ from $0.016 \mathrm{~Hz}$ to $1 \mathrm{kHz}$ and then displayed on a thermalwriting chart recorder (Hewlett-Packard 7758A) with greater than $50 \mathrm{~Hz}$ bandwidth. A parallel output from each amplifier was recorded on an FM magnetic tape recorder (Hewlett-Packard $3960 \mathrm{~A}$, bandwidth DC to $300 \mathrm{~Hz}$ ) for later FFT analysis.

\section{METHODS OF ANALYSIS}

Each recording was analysed visually and by computerised frequency spectrum determination. By these methods the percentage incidence of the slower rhythm in the region of 2 to 4 cycles $/ \mathrm{min}$ $(0.033-0.066 \mathrm{~Hz})$ and the faster rhythm of about 6 to 12 cycles/min $(0 \cdot 1-0 \cdot 2 \mathrm{~Hz})$ for both the monopolar and bipolar recordings was determined. No attempt was made to quantify the actual frequencies, as the object of the study was to compare the visual and automated methods of analysis in terms of percentage incidence of slow wave activity.

In the visual analysis method the presence of regular slow wave activity was observed by inspection of the complete record, and the time during which regular slow wave activity was present at the higher and lower frequency bands was expressed as a percentage of the total recording time. It is important to note that very frequently these occurrences were only of approximately one to two minutes' duration.

The computerised method of analysis used was the Fast Fourier Transform technique. This produces a graph of frequency horizontally with the amplitude of each frequency component vertically and is called the frequency spectrum. The recordings were digitised at an equivalent sampling frequency of $1 \mathrm{~Hz}$ with prior analogue low-pass filtering of cut-off frequency $0.33 \mathrm{~Hz}$ and a slope of $24 \mathrm{~dB} /$ octave. Such pre-filtering is essential to prevent 'aliasing' and the sampling frequency must be sufficiently high to include all frequencies of importance in the data up to half the sampling frequency. The amount of digitised data used in the FFT is of crucial importance in the detection of distinct rhythms in the frequency spectrum. Ideally, a long record should be used to give good frequency resolution. In the colon this is not feasible as the slow-waves do not occur with large amplitude for long periods of time. In the analysis presented here, 256 data points were used for each transform representing about four minutes real-time recording. This gave a frequency discrimination of 0.004 $\mathrm{Hz}$ which was considered to be minimal in distinguishing genuine slow-waves from low-frequency artefact. Although shorter time periods have been used by other workers (Bardakjian et al., 1976; Darby et al., 1978), the frequency resolution is too poor to pick out a spectral peak embedded in the background noise spectrum, which has a predominantly low frequency content in most in vivo biological studies.

The visual and FFT analyses were performed independently by different observers, each of whom was unaware of the results of the other analytical method. Comparison of results was not made until all records had been processed. This point is important as a degree of subjectiveness is involved in determining if a peak in the frequency spectrum is significant. Although automatic significance testing has been used on some gut signals (Smallwood et al., 1975), the colonic records and transforms do not lend themselves to such significance testing, and visual detection of peaks is mandatory.

\section{Results}

Each recording was split into four minute stretches and analysed in the manner described in the previous section. A comparison of the visual and FFT analyses for each four minute stretch of data for one recording (C23) is shown in Table 1. It can be seen that the visual method was likely to give lower estimates of incidence as regular activity could be present for as little as one minute periods. In contrast, the FFT gave a minimum duration indication of about four minutes. This overemphasis was partly counterbalanced by the fact that short durations were unlikely to give a significant peak in the FFT and would therefore be underestimated as zero occurrence. It should be noted that only 
Table 1 Analysis of electrical activity of record C23

\begin{tabular}{|c|c|c|c|c|c|c|c|c|}
\hline \multirow[t]{3}{*}{ Time (min) } & \multicolumn{4}{|l|}{ Monopolar } & \multicolumn{4}{|l|}{ Bipolar } \\
\hline & \multicolumn{2}{|l|}{$3 / \min$} & \multicolumn{2}{|l|}{$12 / \min$} & \multicolumn{2}{|l|}{$3 / \min$} & \multicolumn{2}{|l|}{$12 / \min$} \\
\hline & Visual (min) & $F F T$ & Visual (min) & $F F T$ & Visual (min) & $F F T$ & Visual (min) & $F F T$ \\
\hline $0-4 \cdot 3$ & 41 & $\sqrt{ }$ & 0 & $\sqrt{ }$ & 3 & $\sqrt{ }$ & 2 & $\sqrt{ }$ \\
\hline $4 \cdot 3-8 \cdot 5$ & $4 \frac{1}{4}$ & $\sqrt{ }$ & 0 & $\sqrt{ }$ & 3 & $\sqrt{ }$ & 3 & $\sqrt{ }$ \\
\hline $8 \cdot 5-12 \cdot 8$ & 2 & - & 1 & $\sqrt{ }$ & 2 & - & $2 \frac{1}{2}$ & $\sqrt{ }$ \\
\hline $12 \cdot 8-17 \cdot 0$ & $1 \frac{1}{2}$ & $\sqrt{ }$ & 2 & $\sqrt{ }$ & 0 & $\sqrt{ }$ & $4 \frac{1}{4}$ & $\sqrt{ }$ \\
\hline $17 \cdot 0-21 \cdot 3$ & 0 & - & 3 & $\sqrt{ }$ & 0 & - & 3 & $\sqrt{ }$ \\
\hline $21 \cdot 3-25 \cdot 6$ & 2 & - & 0 & - & $1 \frac{1}{2}$ & - & 1 & $\sqrt{ }$ \\
\hline $25 \cdot 6-29 \cdot 8$ & 2 & - & $1 \frac{1}{2}$ & $\sqrt{ }$ & $1 \frac{1}{2}$ & - & 2 & $\sqrt{ }$ \\
\hline $29 \cdot 8-34 \cdot 1$ & 0 & $\sqrt{ }$ & 1 & - & 0 & - & 41 & $\sqrt{ }$ \\
\hline $34 \cdot 1-38 \cdot 3$ & 3 & $\sqrt{ }$ & 0 & - & $2 \frac{1}{2}$ & $\sqrt{ }$ & 0 & - \\
\hline $38 \cdot 3-42 \cdot 6$ & $2 \frac{1}{2}$ & $\sqrt{ }$ & 2 & - & $2 \frac{1}{2}$ & - & 3 & - \\
\hline $42 \cdot 6-46 \cdot 9$ & 0 & $\sqrt{ }$ & 3 & $\sqrt{ }$ & 0 & - & 2 & - \\
\hline $46 \cdot 9-51 \cdot 1$ & 0 & $\sqrt{ }$ & 2 & $\sqrt{ }$ & 0 & - & 0 & - \\
\hline $51 \cdot 1-55 \cdot 4$ & 41 & $\sqrt{ }$ & 0 & - & 2 & $\sqrt{ }$ & $1 \frac{1}{2}$ & - \\
\hline $55 \cdot 4-59 \cdot 6$ & 0 & - & 2 & $\sqrt{ }$ & 0 & - & 0 & - \\
\hline $59 \cdot 6-63 \cdot 9$ & 41 & $\sqrt{ }$ & 0 & - & 3 & - & $1 \frac{1}{2}$ & $\sqrt{ }$ \\
\hline $63 \cdot 9-68 \cdot 2$ & $4 \frac{1}{4}$ & $\sqrt{ }$ & $1 \frac{1}{2}$ & $\sqrt{ }$ & 3 & $\sqrt{ }$ & 2 & $\sqrt{ }$ \\
\hline $68 \cdot 2-72 \cdot 4$ & 3 & $\sqrt{ }$ & 0 & - & 2 & $\sqrt{ }$ & 0 & - \\
\hline $72 \cdot 4-76 \cdot 7$ & 1 & - & $1 \frac{1}{2}$ & $\sqrt{ }$ & 0 & - & 0 & - \\
\hline $76 \cdot 7-80 \cdot 9$ & $3 \frac{1}{2}$ & $\sqrt{ }$ & 1 & $\sqrt{ }$ & 2 & - & $1 \frac{1}{2}$ & - \\
\hline $80 \cdot 9-85 \cdot 2$ & 41 & $\sqrt{ }$ & 0 & - & 3 & $\sqrt{ }$ & 2 & $\sqrt{ }$ \\
\hline \multirow{2}{*}{$\begin{array}{l}\text { Estimated duration of } \\
\text { activity (min) }\end{array}$} & & & & & & & & \\
\hline & 46 & 60 & $21 \frac{1}{2}$ & 51 & 31 & 34 & $35 \frac{1}{2}$ & 47 \\
\hline
\end{tabular}

Notes:

1. $\sqrt{ }$ : frequency transform in which a significant peak was found, - : no significant peak was found.

2. For the visual analysis, the duration of the activity is the cumulative length of time for which activity was found.

3. For the FFT analysis, the duration of the activity is the cumulative length of the four minute periods in which a significant peak was recognised.

well-defined peaks were taken to be significant, as on many occasions broadly spread spectra around $0.05 \mathrm{~Hz}$ were observed and were caused by lowfrequency artefact (for example, Fig. 1).

From Table 1, it is also clear that the FFT method gave much higher incidence of the faster rhythm. In the visual analysis, frequencies of about $0.2 \mathrm{~Hz}$ were hard to detect as they were often obscured by respiratory signals. In contrast, they were more easily detected by the FFT as there was very little background biological noise near that frequency (for example, Fig. 2).

Tables 2 and 3 show the percentage occurrence of electrical activity in the ascending colon and transverse colon respectively for all patients studied. Both the visual and FFT analyses of the slower ( 3 cycles/min) and faster (12 cycles/min) rhythms are tabulated for the monopolar and bipolar recordings. For each column of data two means \pm 1 standard deviation have been calculated: firstly the mean \pm 1 SD for all data points, and secondly the mean \pm 1 SD of only those records in which all eight analyses (visual and FFT) were available.

From Tables 2 and 3 it can be seen that both electrical rhythms were observed approximately twice as frequently in the transverse colon as in the ascending colon. This was true for both rhythms, monopolar and bipolar recordings, and for both visual and FFT analyses except for the faster rhythm FFT analysis of the bipolar recordings. The mean percentage incidence of both rhythms was never greater than $50 \%$ in either rart of the colon, although in individual patients regular activity was sometimes observed for more than $70 \%$ of the recording period. The total duration of regular activity cannot be calculated by summation of the percentage occurrence of the two rhythms since both rhythms may be observed simultaneously.

In all but the bipolar recordings in the transverse colon both electrical rhythms were detected more frequently by FFT analysis than by visual analysis. This higher detection rate by FFT can be expressed as a ratio between the percentage incidence of the electrical rhythms observed by the visual and FFT methods of analysis. If the visual analysis is used as the reference, then for all recordings the highest ratio was 1:3.7 (monopolar, 3 cycles/min in the ascending colon), and the lowest ratio was $1: 1 \cdot 1$ (bipolar, 3 cycles/min in the transverse colon). For those recordings in which all eight analyses were available (marked by an asterisk in Tables 2 and 3) the highest ratio was $1: 2.9$ and the lowest $1: 1 \cdot 2$.

Comparison of the monopolar and bipolar 

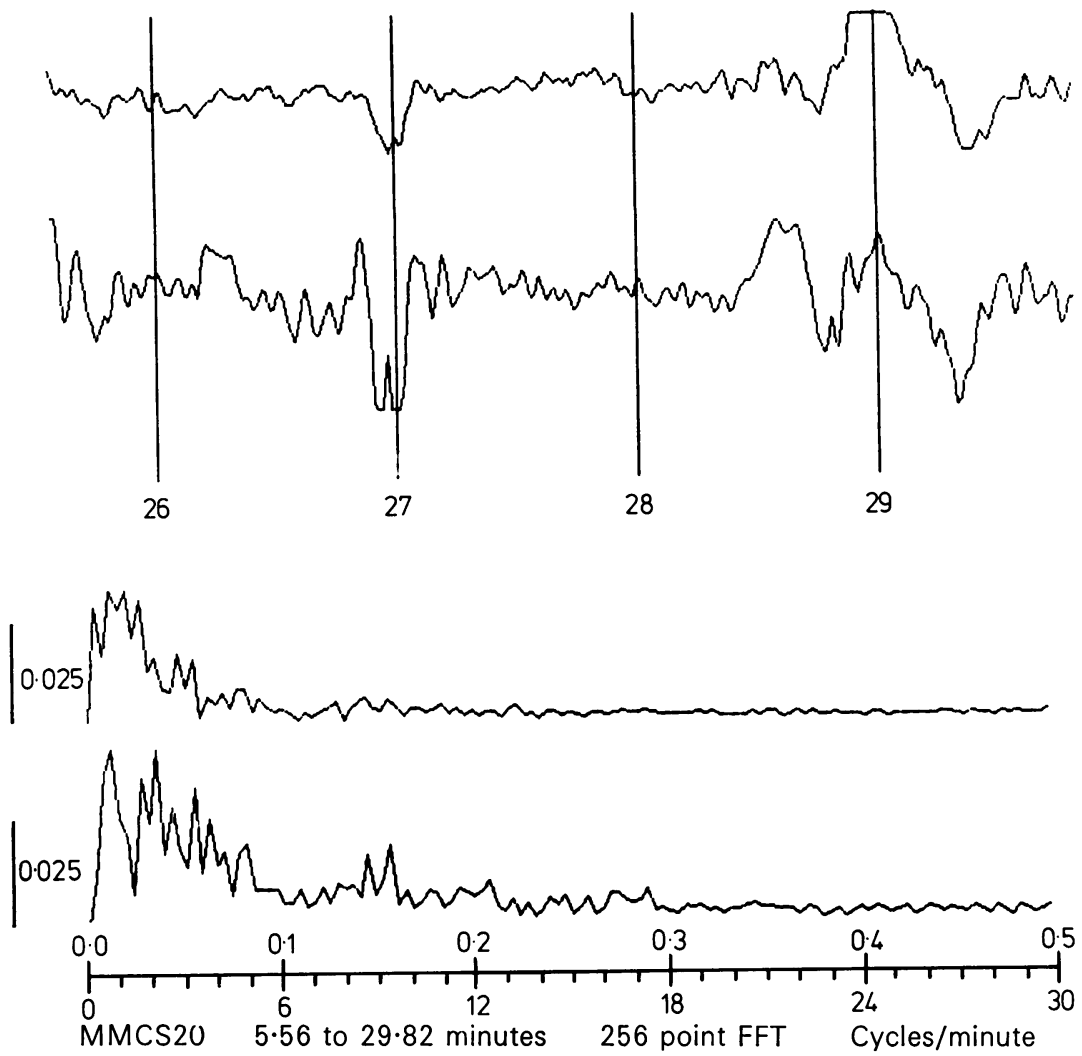

Fig. 1 One 4.26 minute section of record C19. From top to bottom: 1. Electrical signal from the proximal bipolar electrode implanted on the serosal surface of the ascending colon (peak to peak amplitude $500 \mu \mathrm{V}$ ). 2. Electrical signal from the distal monopolar electrode implanted on the serosal surface of the ascending colon (peak to peak amplitude $500 \mu \mathrm{V}$ ). 3. FFT of the proximal bipolar record (amplitude bar calibrated in $m V$ ). 4. FFT of the distal monopolar record (amplitude bar calibrated in $m V)$. Note the movement artefacts in both recordings giving rise to broad peaks in the frequency spectrum in the range 0.02 to $0.07 \mathrm{~Hz}$ (1 to 4 cycle/min).

recordings showed that there was no significant difference in the percentage activity that was recorded by either technique in either part of the colon. The slower rhythm in the transverse colon was detected better on the visual analysis of the bipolar records, but in all others the two rhythms were detected more frequently with the monopolar technique or the percentage occurrences were virtually identical. None of these differences was statistically significant.

\section{Discussion}

Analysis of the records using the FFT method has shown a percentage rhythm incidence of less than $50 \%$ for either mono or bipolar measurements. This contrasts with other workers who have claimed almost $100 \%$ incidence. A major reason for this discrepancy is the use of one minute data lengths by other workers, which gives spurious peak indications at about $0.05 \mathrm{~Hz}$ ( 3 cycles $/ \mathrm{min}$ ) in the presence of low frequency artefact. The discrepancy is also caused by the four minute FFT analysis used in this paper giving no significant peak information when rhythms are present for periods of about one minute's duration.

The differences between rhythm incidence in mono and bipolar electrode measurements is not sufficiently large to account for discrepancies between reported colonic results. In most cases the bipolar recordings gave lower incidence results than for monopolar recordings, whereas workers using bipolar methods have quoted higher incidence 

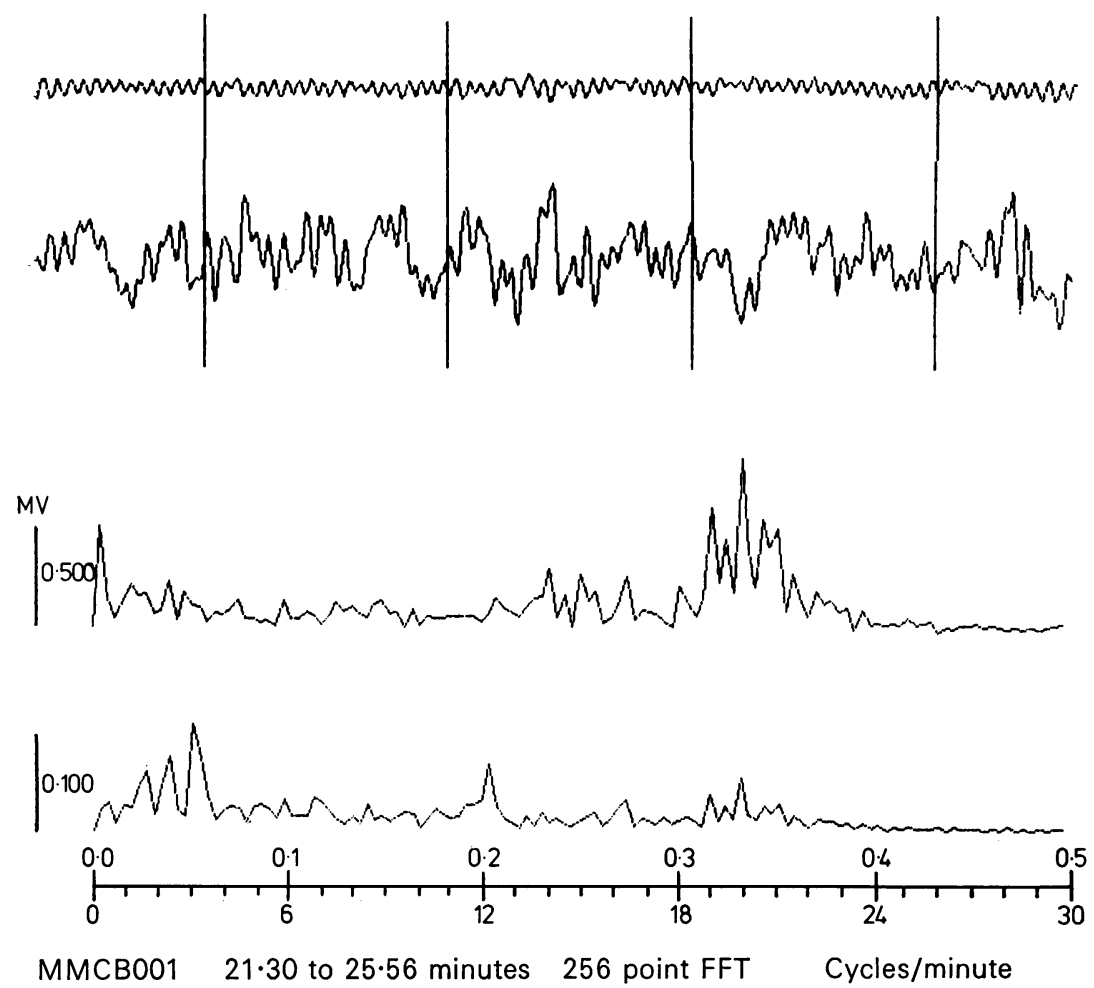

Fig. 2 One 4.26 minute section of record C20. From top to bottom: 1. Respiration. 2. Electrical signal from a bipolar electrode implanted on the serosal surface of the ascending colon (peak to peak amplitude approx. $600 \mu \mathrm{V}$ ), time markers at one minute intervals. Note respiration artefact with no obvious $0.2 \mathrm{~Hz}(12$ cycles/min) activity. 3. Fast Fourier transform of respiration signal (amplitude bar calibrated in $\mathrm{mV}$ ). 4. Fast Fourier transform of colonic signal showing clear peaks at 0.05 and $0.2 \mathrm{~Hz}(3$ and 12 cycles/min) in addition to respiration artefact at $0.33 \mathrm{~Hz}(20$ cycles/min) (amplitude bar calibrated in $\mathrm{mV}$ ).

figures than for those using monopolar techniques.

The incidence of $0.05 \mathrm{~Hz}$ ( 3 cycles $/ \mathrm{min})$ and $0.2 \mathrm{~Hz}$ (12 cycles/min) rhythms in the transverse colon was approximately twice that recorded in the ascending colon. This was true for either mono or bipolar electrodes, and for either visual or FFT methods of analysis. The highest incidence found in all the records was $50 \%$ for FFT analysis of the $0.05 \mathrm{~Hz}$ (3 cycles $/ \mathrm{min})$ rhythm in the transverse colon using monopolar electrodes.

It is concluded that differences in published results for electrical activity of the human colon are not caused by the difference between mono and bipolar electrode waveforms. There are quite large differences in rhythm incidence between different parts of the colon and this may partly account for the discrepancies. The major factor would appear to be the methods of analysis used in obtaining the results. In computerised spectral analysis the time length of data is crucial, particularly for signals whose amplitude varies strongly. Further, the assessment of a significant peak in the spectrum is still a matter of subjective decision, and it is considered that large differences could occur between research groups at this point. The same subjective assessment problem arises, of course, in the visual examination of the raw data. It should be noted that pre-filtering of the data can influence the results obtained. The high-pass filtering used by Bardakjian and his co-workers (1976) has a lower cut-off frequency of $0.16 \mathrm{~Hz}$. This tends to reduce the amplitude of the $0.05 \mathrm{~Hz}$ rhythm and does not explain the discrepancies. A further feature in the methods of analysis is the amplitude of the rhythm. In visual analysis only rhythms above a certain amplitude are normally detected, as recordings are usually made at fixed amplifier gains and little pre-filtering is used. In FFT analysis automatic 
Table 2 Percentage activity in ascending colon

\begin{tabular}{|c|c|c|c|c|c|c|c|c|c|c|}
\hline \multirow[t]{3}{*}{ Record no. } & \multirow[t]{3}{*}{ Sex } & \multirow{3}{*}{$\begin{array}{l}\text { Electrode } \\
\text { position }\end{array}$} & \multicolumn{4}{|c|}{ Monopolar } & \multicolumn{4}{|l|}{ Bipolar } \\
\hline & & & \multicolumn{2}{|l|}{$3 / \min$} & \multicolumn{2}{|l|}{$12 / \mathrm{min}$} & \multicolumn{2}{|l|}{$3 / \min$} & \multicolumn{2}{|l|}{$12 / \min$} \\
\hline & & & Visual & $F F T$ & Visual & $F F T$ & Visual & $F F T$ & Visual & $F F T$ \\
\hline \multirow[t]{2}{*}{ C14* } & $\mathbf{F}$ & Proximal & 7 & 55 & 10 & 30 & 11 & 35 & 2 & 5 \\
\hline & & Distal & 3 & 5 & 2 & 0 & 5 & - & 0 & - \\
\hline \multirow[t]{2}{*}{$\mathrm{C} 15^{*}$} & $\mathbf{F}$ & Proximal & 11 & 38 & 15 & 15 & 10 & 15 & 0 & 0 \\
\hline & & Distal & 6 & 23 & 7 & 0 & 7 & - & 6 & - \\
\hline \multirow[t]{2}{*}{$\mathrm{C} 16^{*}$} & $\mathbf{F}$ & Proximal & 0 & 18 & 24 & 0 & 0 & 41 & 10 & 29 \\
\hline & & Distal & 0 & 47 & 43 & 76 & 0 & - & 10 & 一 \\
\hline \multirow[t]{2}{*}{$\mathrm{C} 17^{*}$} & $\mathbf{F}$ & Proximal & 0 & 5 & 8 & 5 & 2 & 14 & 3 & 14 \\
\hline & & Distal & 3 & 29 & 21 & 10 & 1 & - & 5 & - \\
\hline \multirow[t]{2}{*}{$\mathrm{C} 18^{*}$} & $\mathbf{F}$ & Proximal & 10 & 36 & 13 & 8 & 9 & 28 & 0 & 0 \\
\hline & & Distal & 5 & 48 & 17 & 20 & 8 & - & 0 & - \\
\hline \multirow[t]{2}{*}{ C19* } & $\mathbf{F}$ & Proximal & 4 & 63 & 47 & 63 & 4 & 19 & 15 & 38 \\
\hline & & Distal & 1 & 31 & 37 & 63 & 7 & - & 3 & - \\
\hline C20* & $\mathbf{F}$ & & 26 & 32 & 22 & 43 & 44 & 45 & 36 & 25 \\
\hline C21* & $\mathbf{F}$ & & 18 & 26 & 9 & 21 & 21 & 13 & 0 & 11 \\
\hline $\mathrm{C} 22$ & $\mathbf{F}$ & & 5 & - & 15 & - & 0 & 0 & 23 & 38 \\
\hline $\mathrm{C} 23^{*}$ & F & & 34 & 58 & 18 & 58 & 21 & 31 & 40 & 60 \\
\hline C24* & $\mathbf{M}$ & & 4 & 8 & 0 & 0 & 4 & 4 & 13 & 25 \\
\hline C25* & $\mathbf{M}$ & & 0 & 0 & 0 & 0 & 8 & 0 & 0 & 0 \\
\hline $\mathrm{C} 26^{*}$ & $\mathbf{M}$ & & 2 & 6 & 0 & 0 & 7 & 9 & 0 & 0 \\
\hline \multirow[t]{2}{*}{ C27 } & $\mathbf{F}$ & Proximal & 0 & 0 & 22 & 30 & - & - & - & 一 \\
\hline & & Distal & 2 & 10 & 18 & 25 & - & - & - & - \\
\hline $\mathrm{C} 29^{*}$ & $\mathbf{M}$ & & 2 & 0 & 4 & 8 & 7 & 8 & 0 & 4 \\
\hline \multicolumn{2}{|l|}{ All records } & $\begin{array}{lr}\text { Mean } & \tilde{\mathbf{x}} \\
\text { SD } & \sigma \\
\text { Number } & \mathbf{n}\end{array}$ & $\begin{array}{r}7 \\
\pm 9 \\
22\end{array}$ & $\begin{array}{r}26 \\
\pm 21 \\
21\end{array}$ & $\begin{array}{r}16 \\
\pm 13 \\
22\end{array}$ & $\begin{array}{r}23 \\
\pm 24 \\
21\end{array}$ & $\begin{array}{r}9 \\
+10 \\
20\end{array}$ & $\begin{array}{r}19 \\
\pm 15 \\
14\end{array}$ & $\begin{array}{r}8 \\
\pm 12 \\
20\end{array}$ & $\begin{array}{r}18 \\
\pm 19 \\
14\end{array}$ \\
\hline \multicolumn{2}{|l|}{ Records* } & $\begin{array}{ll}\text { Mean } & \bar{x} \\
\text { SD } & \sigma \\
\text { Number } & n\end{array}$ & $\begin{array}{r}9 \\
+11 \\
13\end{array}$ & $\begin{array}{r}27 \\
\pm 23 \\
13\end{array}$ & $\begin{array}{r}13 \\
\pm 13 \\
13\end{array}$ & $\begin{array}{r}19 \\
\pm 22 \\
13\end{array}$ & $\begin{array}{r}11 \\
\pm 12 \\
13\end{array}$ & $\begin{array}{r}20 \\
\pm 41 \\
13\end{array}$ & $\begin{array}{r}9 \\
+14 \\
13\end{array}$ & $\begin{array}{r}16 \\
\pm 18 \\
13\end{array}$ \\
\hline
\end{tabular}

Notes:

1. All the signals recorded on the chart recorder could not be recorded on magnetic tape; therefore, FFT analysis has not been performed on all the channels of data.

2. 0 : no activity found. - : no analysis performed.

3. *: record on which all eight possible analyses have been performed.

Table 3 Percentage activity in transverse colon

\begin{tabular}{|c|c|c|c|c|c|c|c|c|c|c|}
\hline \multirow[t]{3}{*}{ Record no. } & \multirow[t]{3}{*}{ Sex } & \multirow{3}{*}{$\begin{array}{l}\text { Electrode } \\
\text { position }\end{array}$} & \multicolumn{4}{|c|}{ Monopolar } & \multicolumn{4}{|c|}{ Bipolar } \\
\hline & & & \multicolumn{2}{|l|}{$3 / \min$} & \multicolumn{2}{|l|}{$12 / \mathrm{min}$} & \multicolumn{2}{|l|}{$3 / \min$} & \multicolumn{2}{|l|}{$12 / \mathrm{min}$} \\
\hline & & & Visual & $F F T$ & Visual & $F F T$ & Visual & $F F T$ & Visual & $F F T$ \\
\hline C1 & $\mathbf{F}$ & & 13 & - & 26 & - & - & - & - & - \\
\hline C2 & $\mathbf{F}$ & $\begin{array}{l}\text { Proximal } \\
\text { Distal }\end{array}$ & - & $\overline{-}$ & $=$ & $\overline{-}$ & $\begin{array}{r}4 \\
52\end{array}$ & $\begin{array}{r}5 \\
37\end{array}$ & $\begin{array}{l}0 \\
0\end{array}$ & $\begin{array}{r}5 \\
16\end{array}$ \\
\hline \multirow{2}{*}{$\mathrm{C3}^{*}$} & $\mathbf{M}$ & Proximal & $\overline{26}$ & $\overline{67}$ & $\overline{16}$ & $\overline{54}$ & 33 & 42 & 0 & $\begin{array}{l}10 \\
12\end{array}$ \\
\hline & & Distal & 40 & 83 & 35 & 67 & 74 & 75 & 0 & 8 \\
\hline \multirow{2}{*}{$\mathrm{CH}^{*}$} & $\mathbf{F}$ & Proximal & 2 & 37 & 56 & 59 & 1 & 4 & 54 & 48 \\
\hline & & Distal & 21 & 70 & 28 & 52 & 29 & 41 & 0 & 15 \\
\hline \multirow[t]{2}{*}{ C5 } & $\mathbf{F}$ & Proximal & 22 & - & 17 & - & 24 & - & 0 & - \\
\hline & & Distal & 9 & - & 16 & - & 27 & - & 0 & - \\
\hline C9 & $\mathbf{F}$ & & 20 & - & 15 & - & 27 & - & 3 & - \\
\hline \multirow[t]{2}{*}{ C10* } & $\mathbf{F}$ & Proximal & 26 & 67 & 3 & 4 & 33 & 22 & 0 & 0 \\
\hline & & Distal & 10 & 一 & 12 & - & 12 & 15 & 0 & 0 \\
\hline \multirow[t]{2}{*}{ C11* } & $\mathbf{F}$ & Proximal & 2 & 19 & 8 & 0 & 0 & 27 & 0 & 0 \\
\hline & & Distal & 0 & - & 0 & - & 0 & 11 & 0 & 0 \\
\hline \multirow[t]{2}{*}{$\mathrm{Cl} 2^{*}$} & $\mathbf{M}$ & Proximal & 32 & 47 & 100 & 74 & 30 & 39 & 100 & 48 \\
\hline & & Distal & 0 & 22 & 100 & 61 & 0 & - & 100 & - \\
\hline \multirow[t]{2}{*}{$\mathrm{Cl3}^{*}$} & $\mathbf{M}$ & Proximal & 48 & 61 & 15 & 13 & 65 & 57 & 16 & 4 \\
\hline & & Distal & 34 & 52 & 8 & 13 & 62 & - & 32 & - \\
\hline C28* & $\mathbf{M}$ & & 2 & 0 & 4 & 6 & 24 & 30 & 0 & 3 \\
\hline \multicolumn{2}{|l|}{ All records } & $\begin{array}{lr}\text { Mean } \overline{\mathbf{x}} \\
\text { SD } & \sigma \\
\text { Number } & \end{array}$ & $\begin{array}{r}18 \\
\pm 15 \\
17\end{array}$ & $\begin{array}{r}48 \\
\pm 26 \\
11\end{array}$ & $\begin{array}{r}27 \\
\pm 31 \\
17\end{array}$ & $\begin{array}{r}37 \\
\pm 29 \\
11\end{array}$ & $\begin{array}{r}28 \\
\pm 23 \\
18\end{array}$ & $\begin{array}{r}31 \\
\pm 21 \\
13\end{array}$ & $\begin{array}{r}17 \\
\pm 33 \\
18\end{array}$ & $\begin{array}{r}12 \\
\pm 17 \\
13\end{array}$ \\
\hline \multicolumn{2}{|l|}{ Records* } & $\begin{array}{ll}\text { Mean } & \mathbf{x} \\
\text { SD } & \sigma \\
\text { Number } & \end{array}$ & $\begin{array}{r}22 \\
\pm 17 \\
9\end{array}$ & $\begin{array}{r}50 \\
\pm 27 \\
9\end{array}$ & $\begin{array}{r}29 \\
+31 \\
9\end{array}$ & $\begin{array}{r}37 \\
\pm 30 \\
9\end{array}$ & $\begin{array}{r}32 \\
\pm 25 \\
9\end{array}$ & $\begin{array}{r}37 \\
\pm 20 \\
9\end{array}$ & $\begin{array}{r}19 \\
+35 \\
9\end{array}$ & $\begin{array}{r}15 \\
+19 \\
9\end{array}$ \\
\hline
\end{tabular}



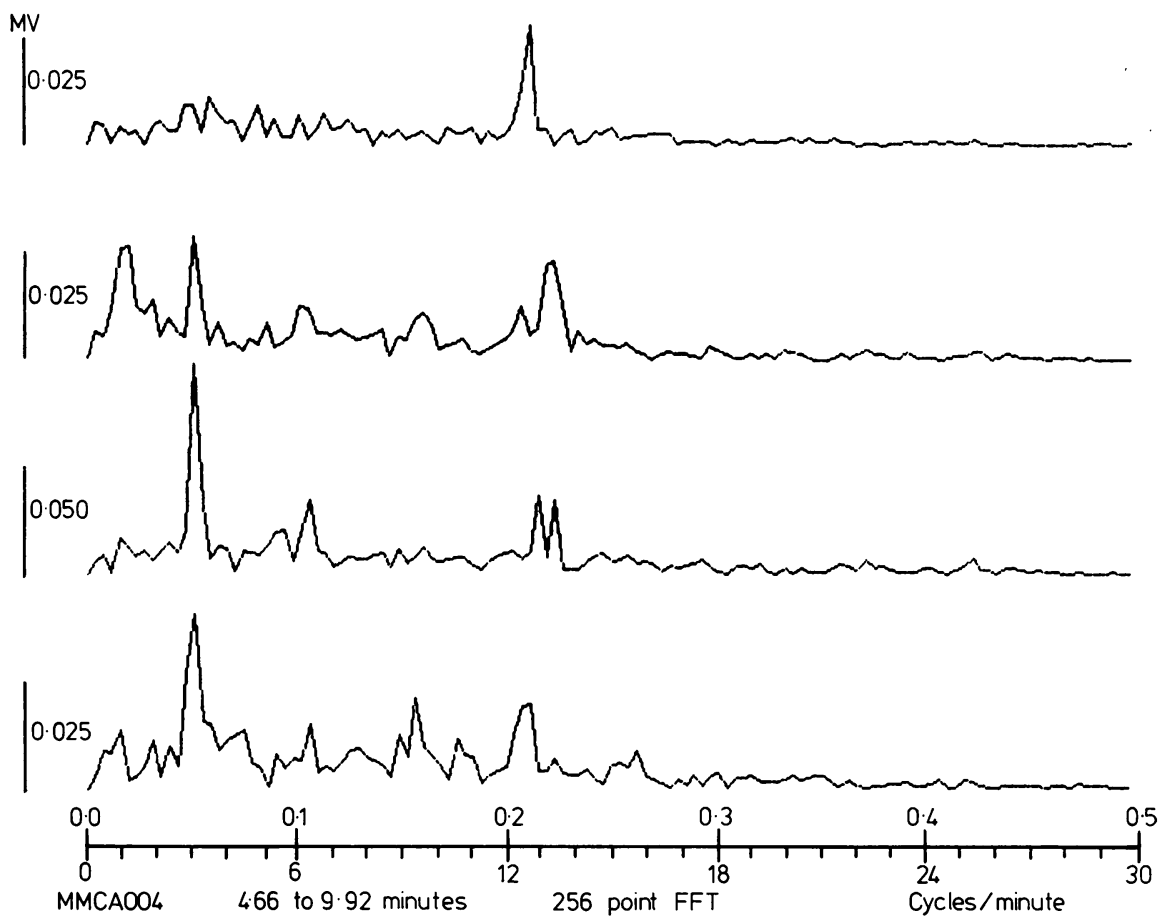

Fig. 3 Fast Fourier transform of one 4.26 minute section of record C23 (amplitude bars calibrated in $\mathrm{mV}$ ): 1. FFT of bipolar recording from the serosal surface of the duodenum. 2. FFT of bipolar recording from the serosal surface of the ascending colon. 3. FFT of monopolar recording from the serosal surface of the ascending colon. 4. FFT of monopolar recording from the serosal surface of the duodenum. Note that the $0.2 \mathrm{~Hz}(12 \mathrm{cycles} / \mathrm{min})$ electrical activity in the ascending colon is at a higher frequency than that recorded from the pylorus.

scaling is usually employed so that peaks which appear to be significant may have very small amplitudes commensurate with the noise in the measurement. Whereas the FFT method can give spurious indications at $0.05 \mathrm{~Hz}(3$ cycles $/ \mathrm{min})$ because of the low frequency spectrum of biological noise in the human colon, it appears to be much better at detecting rhythms at about $0.2 \mathrm{~Hz}(12$ cycles/min) where the background noise spectrum is small.

To show that the higher frequency colonic rhythm does not originate from small bowel slow-waves, certain experiments also recorded activity from the pyloric region. As this is the site of the highest small bowel slow-wave frequency, any colonic activity higher than this cannot be caused by any form of pick-up from the small bowel. An example of this is shown in Fig. 3 where the colonic higher frequency rhythm has a higher frequency than that recorded from the antrum, which itself shows the highest duodenal rhythm.

\section{References}

Bardakjian, B., Sarna, S. K., Waterfall, W. E., Daniel, E. E., and Lind, J. F. (1976). Control function of human colonic electrical activity analysed by computer. Gastroenterology, 70, 861. (Abstract).

Bowes, K. L., Shearin, N. L., Kingma, Y. J., and Koles, Z. J. (1978). Frequency analysis of electrical activity in dog colon. In Gastrointestinal Motility in Health and Disease, pp. 251-270. Edited by H. L. Duthie. MTP Press: Lancaster.

Daniel, E. E., Carlow, D. R., Wachter, B. T., Sutherland, W. H., and Bogoch, A. (1959). Electrical activity of the small intestine. Gastroenterology, 37, 268-281.

Darby, C. F., Hammond, P., and Taylor, I. (1978). Real-time analysis of colonic myoelectrical rhythms in disease. In Gastrointestinal Motility in Health and Disease, pp. 287-295. Edited by H. L. Duthie. MTP Press: Lancaster.

Kelly, K. A., Code, C. F., and Elveback, L. R. (1969). Patterns of canine gastric electrical activity. American Journal of Physiology, 217, 461-470.

Kwong, N. K., Brown, B. H., Whittaker, G. E., and Duthie, H. L. (1970). Electrical activity of the gastric antrum in man. British Journal of Surgery, 57, 913-916.

Linkens, D. A. (1978). Methods of analysing rhythmic electrical potentials in the gastrointestinal tract. In 
Gastrointestinal Motility in Health and Disease. pp. 235-250. Edited by H. L. Duthie, MTP Press: Lancaster.

Smallwood, R. H., Brown, B. H., and Duthie, H. L. (1976). An approach to the objective analysis of intestinal smooth muscle electrical potentials recorded from surface electrodes. In Proceedings of the 5th International Symposium on Gastrointestinal Motility, Edited by G. Vantrappen. Typoff Press: Herentals.

Snape, W. J., Jr. Carlson, G. M., and Cohen, S. (1976). Colonic myoelectrical activity in the irritable bowel syndrome. Gastroenterology, 70, 326-330.
Taylor, I., Duthie, H. L., Smallwood, R. H., Brown, B. H., and Linkens, D. A. (1974). The effect of stimulation on the myoelectrical activity of the rectosigmoid in man. Gut, 15, 599-607.

Taylor, I., Duthie, H. L., Smallwood, R. H., and Linkens, D. A. (1975). Large bowel myoelectrical activity in man. Gut, 16, 808-814.

Waterfall, W. E., Duthie, H. L., and Brown, B. H. (1973). The electrical and motor actions of gastrointestinal hormones on the duodenum in man. Gut, 14, 689-696. 